\title{
Crystal structures and magnetic properties of a set of dihalo-bridged oxalamidato copper(II) dimers $\dagger$
}

\author{
Dijana Žilić, ${ }^{a}$ Boris Rakvin, ${ }^{a}$ Dalibor Milić, $\dagger^{\mathrm{b}}$ Damir Pajić, ${ }^{\mathrm{c}}$ Ivica Đilović, ${ }^{\mathrm{b}}$ \\ Massimo Cametti ${ }^{d}$ and Zoran Džolić ${ }^{\star a}$
}

Received 28th March 2014,

Accepted 30th May 2014

\section{Introduction}

Dinuclear copper(II) complexes have attracted considerable interest over the last few decades, not only for the role played in catalytic enzymatic reactions, ${ }^{1}$ but also because they possess the essential structural features for the study of magnetic interactions between two close magnetic centers. ${ }^{2,3}$ Not surprisingly, the different chemical environment around the copper ions may greatly influence the resulting magnetic behavior. Hence, investigations of the magnetic properties of such complexes in light of their relation to structural features are often attempted for the discovery of definite magneto-structural relationships whose utility increases further, the larger their field of applicability is. In general, correlations of this kind are not easily obtained, especially due to a large structural variability. Taking into consideration a smaller ensemble of $\mathrm{Cu}$ (II)

\footnotetext{
${ }^{a}$ Ruder Bošković Institute, Bijenička cesta 54, 10000 Zagreb, Croatia. E-mail: Zoran.Dzolic@irb.hr; Fax: +385 14680 195; Tel: +3851457 1210

${ }^{b}$ Department of Chemistry, Faculty of Science, University of Zagreb, Horvatovac 102A, 10000 Zagreb, Croatia

${ }^{c}$ Department of Physics, Faculty of Science, University of Zagreb, Bijenička cesta 32, 10000 Zagreb, Croatia

${ }^{d}$ Department of Chemistry, Materials and Chemical Engineering "Giulio Natta", Politecnico di Milano, Via L. Mancinelli 7, 20131 Milano, Italy

$\dagger$ Electronic supplementary information (ESI) available: FT-IR spectra and XRPD data of the complexes $\mathbf{L}^{\mathbf{1}}-\mathbf{C l}, \mathbf{L}^{\mathbf{1}}-\mathbf{B r}, \mathbf{L}^{2}-\mathbf{C l}$ and $\mathbf{L}^{\mathbf{2}}-\mathbf{B r}$; Additional crystallographic information; Angular variation of $g$-values and the $W_{\mathrm{pp}}$ linewidths of EPR lines for $\mathbf{L}^{2}-\mathbf{C l}, \mathbf{L}^{\mathbf{1}}-\mathbf{B r}$ and $\mathbf{L}^{2}-\mathbf{B r}$; Curie-Weiss magnetization fitting curves. CCDC 919441-919443.

\$ Present address: Paul Scherrer Institut, 5232 Villigen PSI, Switzerland.
}

complexes, for example, the dihalo-bridged $\mathrm{Cu}(\mathrm{II})$ complexes, ${ }^{4,5}$ the situation improves a little. However, the structural variability remains wide. Indeed, the metal centers can be four- or five-coordinated, depending on the nature of the ligands, and this gives rise to a variety of different structures, ranging from square-pyramid to trigonal bipyramid. ${ }^{6}$

Over the years, several theoretical analyses have been carried out to obtain an empirical relationship between an exchange coupling constant and structural features of copper(II) complexes and to explain different magnetic behaviors, from ferro- to antiferromagnetic interactions. ${ }^{7}$ Magnetostructural correlation in dihalo-bridged copper(II) complexes seems to be more complicated compared to dihydroxo-bridged complexes. $^{8-11}$ It should also be noted that among dihalobridged complexes, the vast majority of reports are related to dichloro species and considerably less information is available on structural and magnetic properties of dibromo-bridged copper(II) dimers. ${ }^{10,12}$

$N, N^{\prime}$-Disubstituted oxalamides have proved to be very useful ligands for designing homo- and heterometallic complexes. ${ }^{13}$ Indeed, they provide a tunable molecular environment due to cis-trans conformational freedom, different coordination geometries and ligand charges availability (for example by $\mathrm{NH}$ deprotonation). On the other hand, studies on the metal complexes involving oxalyl retro-peptide ligands are very limited. Given the interesting properties that the above mentioned ligands might bring about, we have designed and synthesized four dihalo-bridged copper(II) oxalamidato dimers: $\left[\mathrm{CuL}^{\mathbf{1}}(\mu-\mathrm{Cl})\right]_{2} \cdot \mathrm{CH}_{3} \mathrm{OH} \quad\left(\mathbf{L}^{\mathbf{1}}-\mathbf{C l}\right), \quad\left[\mathrm{CuL}^{2}(\mu-\mathrm{Cl})\right]_{2} \quad\left(\mathbf{L}^{2}-\mathbf{C l}\right)$, $\left[\mathrm{CuL}^{\mathbf{1}}(\mu-\mathrm{Br})\right]_{2}\left(\mathbf{L}^{\mathbf{1}}-\mathbf{B r}\right)$ and $\left[\mathrm{CuL}^{2}(\mu-\mathrm{Br})\right]_{2}\left(\mathbf{L}^{\mathbf{2}}-\mathbf{B r}\right)$, where ligands 


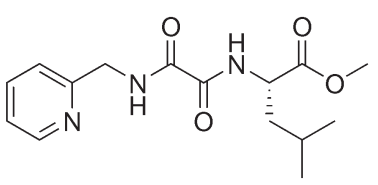

$L^{1}$

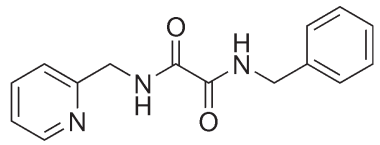

$L^{2}$
Fig. 1 Schematic presentation of ligands $N$-(L-leucine methyl ester)- $N^{\prime}$ ((2-pyridin-2-yl)methyl)oxalamide $\left(\mathrm{L}^{1}\right)$ and $N$-benzyl- $N^{\prime}-((2-$ pyridin-2-yl) methyl)oxalamide $\left(\mathrm{L}^{2}\right)$.

$\mathbf{L}^{1}$ and $\mathbf{L}^{2}$ stand for $N$-(L-leucine methyl ester)- $N^{\prime}$-((2-pyridin-2yl)methyl)oxalamide and $N$-benzyl- $N^{\prime}$-((2-pyridin-2-yl)methyl)oxalamide, respectively (Fig. 1).

To the best of our knowledge, the described compounds represent the first set of structures of oxalamido-complexes which display discrete dinuclear dihalo-bridged units.

The magnetic characterization of the compounds was performed by Electron Paramagnetic Resonance (EPR) spectroscopy and SQUID magnetization measurements. Single crystal EPR spectroscopy performed on the dinuclear copper complexes provided information about the coordination geometry around copper(II) ions. Moreover, from the angular dependence of linewidth, additional information about the mechanism of interaction between copper(II) ions was obtained. Temperature and field dependencies of magnetization were used for the determination isotropic exchange interaction between copper ions. Finally, a relation between magnetic behavior and molecular structure of the investigated complexes has been presented and discussed in the framework of existing correlations for dihalo-bridged copper(II) complexes.

\section{Materials and methods}

The preparation and structural details of ligands $\mathbf{L}^{1}$ and $\mathbf{L}^{2}$ have been previously described. ${ }^{14}$ Complexes $\mathbf{L}^{1}-\mathbf{C l}, \mathbf{L}^{2}-\mathbf{C l}$, $\mathbf{L}^{1}-\mathbf{B r}$ and $\mathbf{L}^{2}-\mathbf{B r}$ were prepared by the reaction of equimolar quantities of ligands with $\mathrm{CuCl}_{2} \cdot 2 \mathrm{H}_{2} \mathrm{O}$ or $\mathrm{CuBr}_{2}$ in methanol. Single crystals suitable for X-ray diffraction were obtained by slow evaporation of corresponding methanol solutions.

FT-IR spectra of all complexes (see Fig. S1 and S2 in ESI $\dagger$ ) were recorded at a resolution of $4 \mathrm{~cm}^{-1}$ on an $\mathrm{ABB}$ Bomem MB102 single beam FT-IR spectrometer at room temperature.

$\mathbf{L}^{1}$-Cl: Anal. calcd for $\mathrm{C}_{31} \mathrm{H}_{44} \mathrm{Cl}_{2} \mathrm{Cu}_{2} \mathrm{~N}_{6} \mathrm{O}_{9}$ : C, 44.19; H, 5.26; $\mathrm{N}, 9.97 ; \mathrm{Cu}, 15.08$. Found $\mathrm{C}, 44.25 ; \mathrm{H}, 5.33 ; \mathrm{N}, 9.89 ; \mathrm{Cu}, 15.06$. IR (KBr): $\nu=3189 ， 3071 ， 2956 ， 1745 ， 1670 ， 1619 ， 1435$, $1416 \mathrm{~cm}^{-1}$.

$\mathbf{L}^{2}$-Cl: Anal. calcd for $\mathrm{C}_{30} \mathrm{H}_{28} \mathrm{Cl}_{2} \mathrm{Cu}_{2} \mathrm{~N}_{6} \mathrm{O}_{4}$ : C, 49.05; H, 3.84; $\mathrm{N}, 11.44 ; \mathrm{Cu}, 17.30$. Found $\mathrm{C}, 48.97 ; \mathrm{H}, 3.88 ; \mathrm{N}, 11.69 ; \mathrm{Cu}$, 17.22. IR (KBr): $\nu=3218,3181,3147,3056,1672,1624,1426$, $1412 \mathrm{~cm}^{-1}$.

$\mathbf{L}^{1}$-Br: Anal. calcd for $\mathrm{C}_{30} \mathrm{H}_{40} \mathrm{Br}_{2} \mathrm{Cu}_{2} \mathrm{~N}_{6} \mathrm{O}_{8}$ : C, 40.06; $\mathrm{H}, 4.48$; N, 9.34; $\mathrm{Cu}, 14.13$. Found C, 39.98; H, 4.58; N, 9.39; Cu, 14.15. IR (KBr): $\nu=3180,3149,3067,2953,1744,1731,1668,1614$, $1437,1430,1414 \mathrm{~cm}^{-1}$.
$\mathbf{L}^{2}$-Br: Anal. calcd for $\mathrm{C}_{30} \mathrm{H}_{40} \mathrm{Br}_{2} \mathrm{Cu}_{2} \mathrm{~N}_{6} \mathrm{O}_{8}: \mathrm{C}, 43.76 ; \mathrm{H}, 3.43$; $\mathrm{N}, 10.20 ; \mathrm{Cu}, 15.43$. Found C, 43.87; H, 3.29; N, 10.29; Cu, 15.44. IR (KBr): $\nu=3211,3182,3143,3058,2935,1663,1617$, $1435,1411 \mathrm{~cm}^{-1}$.

\subsection{X-ray crystallographic study}

We have already reported single-crystal X-ray structural analysis of $\mathbf{L}^{1}$-Cl (CCDC 907166). ${ }^{14}$ X-ray diffraction data from single crystals of $\mathbf{L}^{2}-\mathbf{C l}, \mathbf{L}^{1}-\mathbf{B r}$ and $\mathbf{L}^{2}-\mathbf{B r}$ were collected on an Oxford Diffraction Xcalibur 3 CCD diffractometer with graphite-monochromated MoKo radiation $(\lambda=0.71073 \AA)$ and reduced using the CrysAlis PRO software package. ${ }^{15}$ The solution (SHELXS), ${ }^{16}$ refinement (SHELXL-97), ${ }^{16}$ building and analysis of the structures were performed using $\operatorname{Coot}^{17}$ and the programs integrated in the WinGX system. ${ }^{18}$ Data processing and refinement statistics are given in Table 1. All non-hydrogen atoms were refined anisotropically. $\mathrm{H}$ atoms attached to $\mathrm{C}$ atoms were positioned geometrically and refined isotropically applying the usual riding model $\left[d(\mathrm{C}-\mathrm{H})=0.93-1.00 \AA\right.$ and $U_{\text {iso }}(\mathrm{H})=1.2$ or $\left.1.5 U_{\text {eq }}(\mathrm{C})\right]$. The $\mathrm{H}$ atom attached to $\mathrm{N} 3$ in $\mathbf{L}^{2}-\mathbf{C l}$ was refined isotropically with a restraint on the $\mathrm{N}-\mathrm{H}$ distance (DFIX 0.86 0.02), while $\mathrm{H}$ atoms of the same type in $\mathbf{L}^{1}-\mathbf{B r}$ and $\mathbf{L}^{2}-\mathbf{B r}$ were positioned geometrically and refined using the appropriate riding model [AFIX 43, $d(\mathrm{~N}-\mathrm{H})=0.88 \AA$ and $U_{\text {iso }}(\mathrm{H})=$ $\left.1.2 U_{\text {eq }}(\mathrm{N})\right]$. The $N$-benzyl moiety in $\mathbf{L}^{2}-\mathbf{C l}$ is discretely disordered over two conformations with the relative population parameter $0.840(5)$ for the major one. The disordered atoms in $\mathbf{L}^{\mathbf{2}}-\mathbf{C l}$ were refined with restraints on their geometrical (SAME) and displacement parameters (SIMU, DELU, and ISOR). The final structural models were analyzed using PLATON. ${ }^{19}$ Molecular graphics were prepared in Mercury, ${ }^{20}$ ORTEP-3, ${ }^{21}$ and POV-Ray. ${ }^{22}$

The phase purity of each sample was confirmed by X-ray powder diffraction (XRPD) (see Fig. S3-S6 in ESI†). Patterns used for qualitative PXRD analysis of the samples were collected on a Philips PW 3710 diffractometer, CuK $\alpha$ radiation, a flat plate sample on a zero background in Bragg-Brentano geometry, tension $40 \mathrm{kV}$, current $40 \mathrm{~mA}$. The patterns were collected in the angle region between $4^{\circ}$ and $40^{\circ}(2 \Theta)$ with a step size of $0.02^{\circ}$ and $1.0 \mathrm{~s}$ counting per step.

\subsection{EPR study}

EPR measurements were performed on the single crystals and on the powder forms of the investigated compounds. EPR experiments were carried out with a Bruker $580 \mathrm{FT} / \mathrm{CW}$ X-band spectrometer equipped with a standard Oxford Instruments model DTC2 temperature controller. The microwave frequency was $\approx 9.6 \mathrm{GHz}$ with the magnetic field modulation amplitude of $0.5 \mathrm{mT}$ at $100 \mathrm{kHz}$. The crystals of chloride (bromide) compounds were elongated along the crystallographic $b(a)$-axis. They were rotated around three mutually orthogonal axes: a crystallographic $b(a)$-axis, an arbitrary chosen $c^{*}\left(b^{*}\right)$-axis perpendicular to $b(a)$-axis and a third $a^{*}\left(c^{*}\right)$-axis, perpendicular to the previous two axes. EPR spectra were recorded at $5^{\circ}$ steps and the rotation was controlled by a home-made goniometer with the accuracy of $1^{\circ}$. A larger uncertainty $\left(2-3^{\circ}\right)$ was related 
Table 1 X-ray crystallographic data for $\mathrm{L}^{2}-\mathrm{Cl}, \mathrm{L}^{1}-\mathrm{Br}$ and $\mathrm{L}^{2}-\mathrm{Br}$

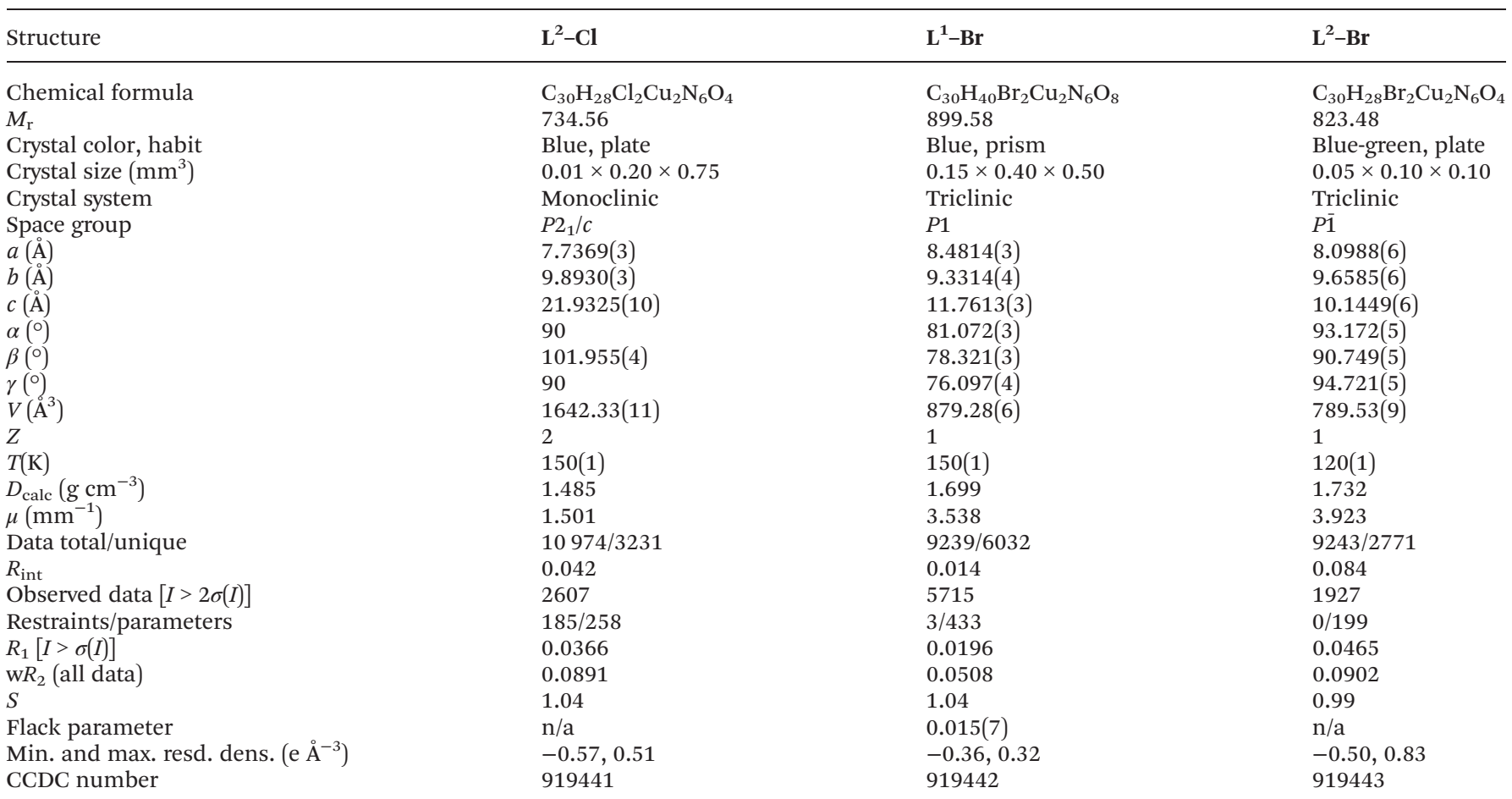

to the optimal deposition of the crystals on the quartz holder. The EPR spectra were measured at two temperatures: $T=297 \mathrm{~K}$ and $T=80 \mathrm{~K}$.

\subsection{Magnetization study}

Magnetic measurements of the investigated compounds in the form of powders were performed using a commercial MPMS5 SQUID magnetometer. Temperature dependent magnetization $M(T)$ for $2 \mathrm{~K}<T<300 \mathrm{~K}$ was measured in a constant magnetic field of 1000 Oe and, after correction against the sample holder, the temperature independent contributions of inner electrons were also subtracted. The field dependence of magnetization $M(H)$ was measured at a lowest temperature of $2 \mathrm{~K}$ in field up to $5 \mathrm{~T}$.

\section{Results and discussion}

\subsection{Description of structures}

Oxalyl retro-peptide compounds represent a versatile class of molecules which has been previously employed, with considerable success, in the study of gel formation. ${ }^{23}$ There are only a few examples of structurally characterized halo-bridged oxalamidato metal complexes. ${ }^{24-26}$ Mixing equimolecular amounts of $\mathrm{CuCl}_{2} \cdot 2 \mathrm{H}_{2} \mathrm{O}$ or $\mathrm{CuBr}_{2}$ and the asymmetrical $N, N^{\prime}$-disubstituted oxalamide ligands $\mathbf{L}^{1}$ and $\mathbf{L}^{2}$ in $\mathrm{MeOH}$ did not result in oxalamidato-bridged complexes, as in the case of copper(II) nitrate or perchlorate and the symmetrical $N, N^{\prime}$-bis-(2-methylpyridyl)-oxalamide. ${ }^{27}$ Instead, the dihalo-bridged dinuclear complexes $\mathbf{L}^{\mathbf{1}}$ - and $\mathbf{L}^{\mathbf{2}}-\mathbf{X}(\mathrm{X}=\mathrm{Cl}$ and $\mathrm{Br}$ ) were obtained (Fig. 2).
In all cases, the X-ray determined structures of the complexes show penta-coordinated $\mathrm{Cu}(\mathrm{II})$ ions adopting a square pyramidal geometry. The square base coordination sites are occupied by a deprotonated ligand, acting as NNO tridentate, and by one of the bridging halo-ions; the apical position of the pyramid is instead occupied by the other bridging halo-ion, as shown in Fig. 3. The coordination polyhedron around the copper(II) ion could be best described as an ideal or near ideal square pyramid, with $\tau=0.00-0.17$ (where $\tau=0$ implies the ideal square-pyramidal geometry and $\tau=1$ an ideal trigonal bipyramid; ${ }^{28}$ Table 2). As said, the two $\mathrm{Cu}(\mathrm{II})$ centers are bridged by two halo-ions in such a way that the two square pyramids share one base-to-apex edge while having their basal planes parallel (Fig. 3). Rodríguez et al. have designated this kind of configurations for copper complex containing the $\mathrm{Cu}-(\mu-\mathrm{X})_{2}-$ $\mathrm{Cu}$ core as a type II pyramidal arrangement. ${ }^{29}$ Although the dimeric molecules with achiral ligand $\mathbf{L}^{2}$ are positioned on the crystallographic inversion centers, $N$-benzyl groups in $\mathbf{L}^{2}-\mathbf{C l}$ are discretely disordered over two conformations (Fig. 2).

Bond distances and angles relevant to the coordination of copper(II) ions are given in Table 2. The $\mathrm{Cu}_{2} \mathrm{X}_{2}$ unit is planar in all the four dimers with the bridging $\mathrm{Cu}-\mathrm{X}-\mathrm{Cu}^{\prime}$ angles $[86.53$ (3) $\left.-91.50(3)^{\circ}\right]$ being close to a right angle and the $\mathrm{Cu} \cdots \mathrm{Cu}^{\prime}$ intra-dimeric distances ranging from $3.4408(4)$ to $3.6852(6) \AA$. Similarly as in other dihalo-bridged $\mathrm{Cu}(\mathrm{II})$ complexes with square-pyramidal coordination, ${ }^{30,31}$ the axial $\mathrm{Cu}-\mathrm{X}$ bonds $[2.6674(8)-2.7582(6) \AA$ in the Cl-complexes and 2.7475(9)2.8282(5) $\AA$ in the Br-complexes] are significantly longer than the corresponding basal $\mathrm{Cu}-\mathrm{X}$ bonds [2.2221(6)-2.2443(8) $\AA$ in the Cl-complexes and 2.3910(5)-2.4056(9) $\AA$ in the Br-com- 

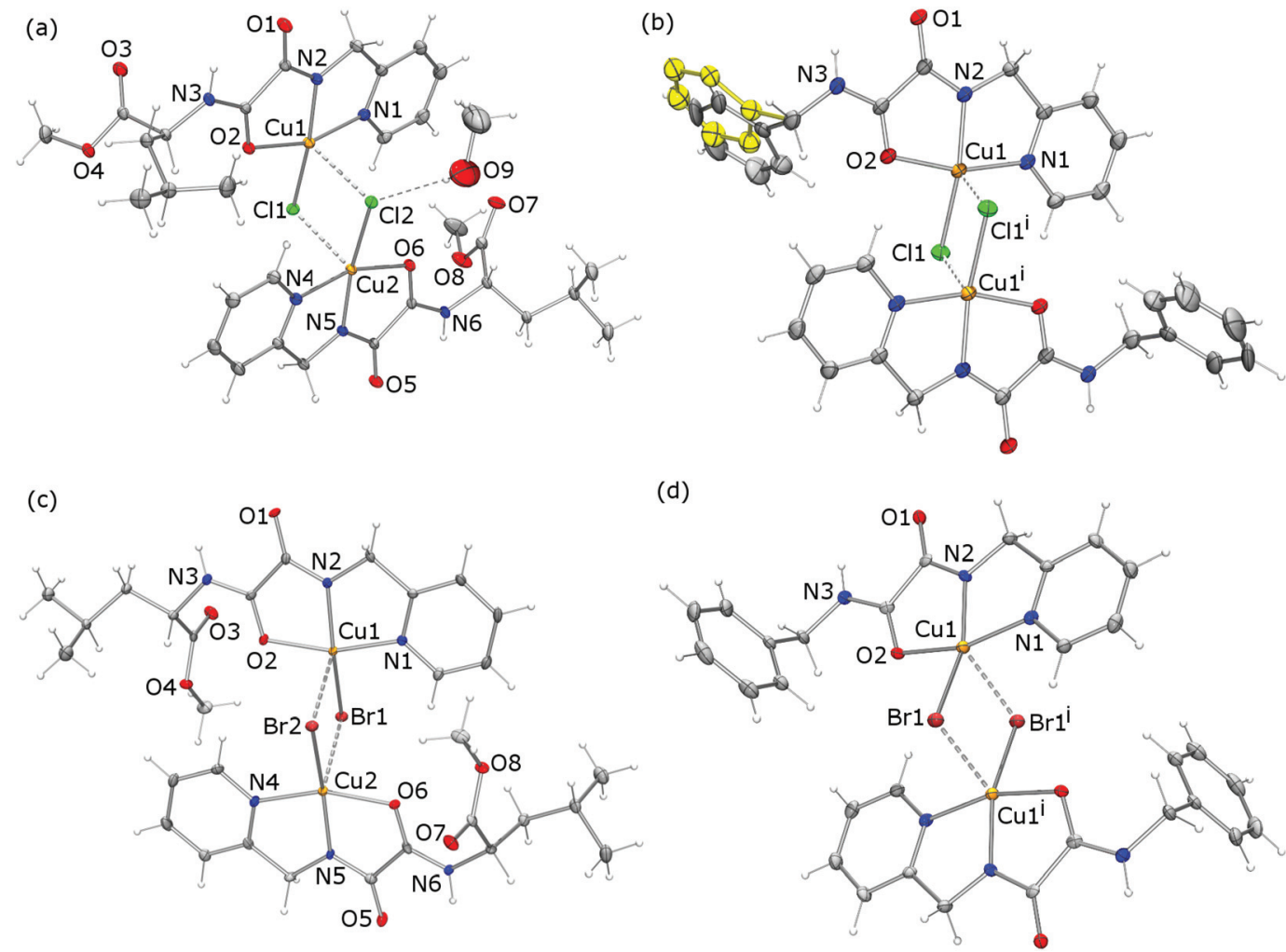

Fig. 2 The molecular structures of complexes (a) $\mathrm{L}^{1}-\mathrm{Cl}$, (b) $\mathrm{L}^{2}-\mathrm{Cl}$, (c) $\mathrm{L}^{1}-\mathrm{Br}$ and (d) $\mathrm{L}^{2}-\mathrm{Br}$. Displacement ellipsoids are drawn at the $30 \%$ probability level. $\mathrm{H}$ atoms are shown as spheres of an arbitrary radius. Dashed lines represent the $\mathrm{O}-\mathrm{H} \cdots \mathrm{Cl}$ hydrogen bond in $\mathrm{L}^{1}-\mathrm{Cl}$ and the apical $\mathrm{Cu}-\mathrm{X}$ bonds $\left(\mathrm{X}=\mathrm{Cl}\right.$ or $\mathrm{Br}$ ) in all the complexes. Atoms labeled with " $\mathrm{i}$ " in $\mathrm{L}^{2}-\mathrm{Cl}$ and $\mathrm{L}^{2}-\mathrm{Br}$ are centrosymmetrically related to those in the other half of a molecule. The less populated conformation [the relative population parameter $0.160(5)$ ] of the disordered $\mathrm{N}$-benzyl group in $\mathrm{L}^{2}-\mathrm{Cl}$ (yellow) is shown only for a crystallographically independent half of the dinuclear complex. Although modeled, $\mathrm{H}$ atoms in this conformation are not depicted for clarity.

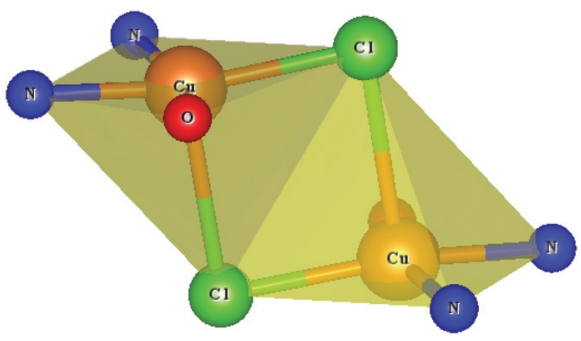

Fig. 3 For all the investigated compounds, the coordination environment around $\mathrm{Cu}(I)$ is an ideal or near ideal square-pyramidal. $\mathrm{Cu}(I)$ ions are penta-coordinated by an oxalamidato $\mathrm{O}$ and $\mathrm{N}$, pyridyl $\mathrm{N}$ atom and two halo-ions $\left(\mathrm{X}^{-} ; \mathrm{X}=\mathrm{Cl}\right.$ or $\left.\mathrm{Br}\right)$. The halo-ion that is farther from the $\mathrm{Cu}(I)$ occupies the apical position of the square pyramid. Two pyramids share one base-to-apex edge with the parallel basal plane.

plexes], due to the Jahn-Teller effect. However, the coordination to a negatively charged ligand (at the oxalamidato $\mathrm{N}$ atoms $\mathrm{N} 2$ or $\mathrm{N} 5)$ shortens the observed $\mathrm{Cu}-\mathrm{N}$ (oxalamide) bonds in all complexes $[1.896(4)-1.917(4) \AA]$ with respect to the usual $\mathrm{Cu}-\mathrm{N}$ (pyridyl) bonds [1.996(4)-2.034(4) $\AA$ ] , observed in similar copper(II) complexes, for example those made of $N, N^{\prime}$-bis-(2-methylpyridyl)-oxalamide. ${ }^{27}$

Within the crystal, in all cases, the complexes are linked to each other by hydrogen bonds between oxalamide units
(Fig. 4; Table 5 in the ESI $\dagger$ ) and form infinite chains of dinuclear units. Such a supramolecular arrangement resembles the structure of the only linear-chain $\mathrm{Cu}(\mathrm{II})$ compound reported so far which displays alternating dichloro- and oxalamidato-bridges. ${ }^{24}$ Stacking interactions between pyridyl and metalloaromatic chelate rings ${ }^{32}(\mathrm{Cu}-\mathrm{O}-\mathrm{C}-\mathrm{C}-\mathrm{N}$ in our case), which we have observed for $\mathbf{L}^{1}-\mathbf{C l},{ }^{14}$ are also present in crystal structures of the bromo-complexes (Table 6 and Fig. S10 and S11 in ESI $\dagger$ ), but - surprisingly - not in $\mathbf{L}^{2}-\mathbf{C l}$. In addition, we also found weak hydrogen bond $\mathrm{C}-\mathrm{H} \cdots A$ and $\mathrm{C}-\mathrm{H} \cdots \pi$ interactions with either a chelate ${ }^{33}$ or a phenyl ring (as detailed in Tables 5 and 7 in ESI $\dagger$ ). Intriguingly, the crystal packing of $\mathbf{L}^{2}-\mathbf{C l}$ molecules allows discrete conformational disorder of their $N$-benzyl groups (Fig. S9 in ESI $\dagger$ ), while preserving C$\mathrm{H} \cdots \pi$ interactions for both observed conformations (Table 7 in ESI $\dagger$ ). An aryl $\pi-\pi$ stacking interaction exists only between two phenyl rings in the crystal structure of $\mathbf{L}^{2}-\mathbf{B r}$ (Fig. S11 and Table 6 in ESI†). A more detailed description of crystal packing is provided in ESI. $\dagger$

\section{2. $\quad$ EPR study}

The single crystal EPR spectrum of the complex $\mathbf{L}^{1}-\mathbf{C l}$ shows a single, fairly Lorentzian, line in every direction of the magnetic field. Similar spectra are also observed for the dibromobridged complexes $\mathbf{L}^{1}-\mathbf{B r}$ and $\mathbf{L}^{2}-\mathbf{B r}$. Differently, the complex 
Table 2 Molecular geometry $\left(\AA^{,},{ }^{\circ}, \AA^{-1}\right)$ of the analyzed complexes

\begin{tabular}{|c|c|c|c|c|c|c|}
\hline & $\mathbf{L}^{1}-\mathbf{C l}^{a 14}$ & & $\mathrm{~L}^{2}-\mathrm{Cl}$ & $\mathbf{L}^{1}-\mathbf{B r}^{a}$ & & $\mathbf{L}^{2}-\mathbf{B r}$ \\
\hline $\mathrm{Cu}-\mathrm{X}^{b}$ (basal) & $2.2221(6)$ & $2.2552(6)$ & $2.2443(8)$ & $2.4001(5)$ & $2.3910(5)$ & $2.4056(9)$ \\
\hline $\mathrm{Cu}-\mathrm{X}$ (axial) (R) & $2.7582(6)$ & $2.7049(6)$ & $2.6674(8)$ & $2.8282(5)$ & $2.8071(5)$ & $2.7475(9)$ \\
\hline $\mathrm{Cu}-\mathrm{O}$ (oxalamide) & $2.064(2)$ & $2.052(2)$ & $2.010(2)$ & $2.013(3)$ & $2.055(3)$ & $2.026(3)$ \\
\hline $\mathrm{Cu}-\mathrm{N}$ (pyridyl) & $2.030(2)$ & $2.014(2)$ & $2.003(2)$ & $1.996(4)$ & $2.034(4)$ & $2.007(4)$ \\
\hline $\mathrm{Cu}-\mathrm{N}$ (oxalamide) & $1.899(2)$ & $1.906(2)$ & $1.910(2)$ & $1.917(4)$ & $1.910(4)$ & $1.896(4)$ \\
\hline$\tau^{c}$ & 0.17 & 0.15 & 0.02 & 0.04 & 0.00 & 0.10 \\
\hline$d(\mathrm{Cu})^{d}$ & $0.1310(2)$ & $0.1828(2)$ & $0.1990(3)$ & $0.2282(4)$ & $0.2362(5)$ & $0.2492(7)$ \\
\hline $\mathrm{Cu} \cdots \mathrm{Cu}^{\prime}$ & \multicolumn{2}{|c|}{$3.5239(3)$} & $3.4408(4)$ & \multicolumn{2}{|c|}{$3.6852(6)$} & $3.5405(9)$ \\
\hline $\mathrm{Cu}-\mathrm{X}-\mathrm{Cu}^{\prime}(\alpha)$ & $90.78(2)$ & $88.73(2)$ & $91.50(3)$ & $89.74(2)$ & $89.43(2)$ & $86.53(3)$ \\
\hline$\alpha / R$ & 32.91 & 32.80 & 34.30 & 31.73 & 31.86 & 31.49 \\
\hline
\end{tabular}

${ }^{a}$ Data are given for each of the two crystallographically independent parts of a dinuclear complex. ${ }^{b} \mathrm{X}=\mathrm{Cl}$ or Br. ${ }^{c}$ Reedijk's trigonal distortion $\tau$ (ideally, $\tau=0$ for a square-pyramidal and $\tau=1$ for a trigonal-bipyramidal geometry). ${ }^{14 d}$ Displacement of $\mathrm{Cu}$ atoms from the mean basal plane.
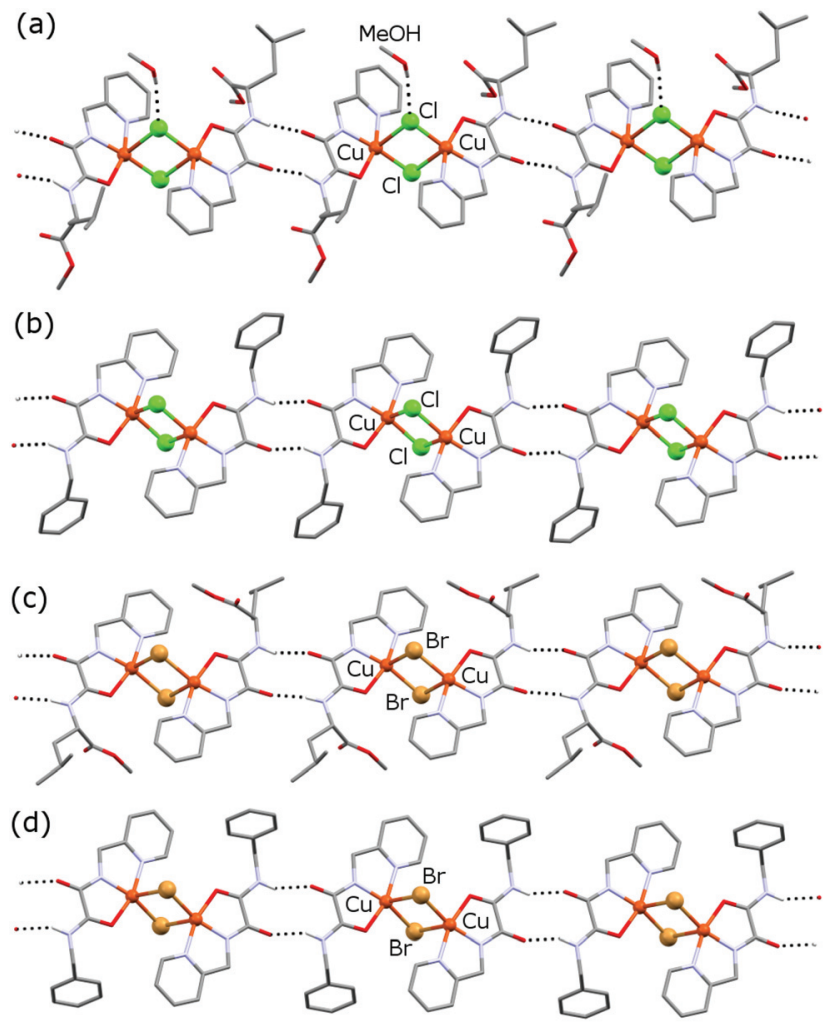

Fig. 4 Infinite molecular chains in the crystal structures of (a) $\mathrm{L}^{1}-\mathrm{Cl}$ (b) $\mathrm{L}^{2}-\mathrm{Cl}$, (c) $\mathrm{L}^{1}-\mathrm{Br}$ and (d) $\mathrm{L}^{2}-\mathrm{Br}$ formed by hydrogen-bonding (dotted lines) between oxalamide units. The minor conformation of the disordered $\mathrm{N}$-benzyl moiety in $\mathrm{L}^{2}-\mathrm{Cl}$ and the $\mathrm{H}$ atoms attached to $\mathrm{C}$ atoms are omitted for clarity.

$\mathbf{L}^{2}$-Cl shows a single line in only one rotation plane and double lines in the other two (except for directions close to the crystal axes). The observed number of EPR lines can be simply correlated to the number of molecules (dimers), $Z$, found in the unit cell. In the $\mathbf{L}^{1}-\mathbf{C l}, \mathbf{L}^{\mathbf{1}}-\mathbf{B r}$ and $\mathbf{L}^{2}-\mathbf{B r}$ complexes $Z=1$, while $Z=2$ for $\mathbf{L}^{2}-\mathbf{C l}$ complex. Moreover, while dimeric units for $\mathbf{L}^{2}$-complexes are crystallographically centrosymmetric and, thus, the two bridged copper centers are magnetically equivalent, different is the case of $\mathbf{L}^{\mathbf{1}}$-complexes whose dimeric units are constituted by magnetically nonequivalent copper ions. Hence, the observation of one line - instead of two lines - in the EPR spectra of the latter compounds points to the existence of exchange interaction with $2 J>\Delta g \beta H$, where $\Delta g$ is the difference between $g$-factors of the copper ions and other symbols have their usual meaning. ${ }^{34}$ Hyperfine interactions or any half-field transitions associated with a $\Delta M_{\mathrm{S}}= \pm 2$ were not detected from room temperature down to $80 \mathrm{~K}$.

Angular dependencies of $g$-factor and peak-to-peak linewidths, $W_{\mathrm{pp}}$, recorded at room temperature, are presented in Fig. 5, as well as in Fig. S12-S14 in ESI. $\dagger$ The dependencies obtained at $T=80 \mathrm{~K}$ were approximately the same as those at room temperature and therefore they are omitted.

The elements of a $\left(\mathbf{g}^{\mathbf{T}} \mathbf{g}\right)$-tensor were determined using the following equation: ${ }^{35}$

$$
\begin{aligned}
g^{2}= & \left(\mathbf{g}^{\mathrm{T}} \mathbf{g}\right)_{\mathrm{aa}} \sin ^{2} \theta \cos ^{2} \phi+\left(\mathbf{g}^{\mathrm{T}} \mathbf{g}\right)_{\mathrm{ab}} \sin ^{2} \theta \sin 2 \phi \\
& +\left(\mathbf{g}^{\mathrm{T}} \mathbf{g}\right)_{\mathrm{bb}} \sin ^{2} \theta \sin ^{2} \phi+\left(\mathbf{g}^{\mathrm{T}} \mathbf{g}\right)_{\mathrm{ac}} \sin 2 \theta \cos \phi \\
& +\left(\mathbf{g}^{\mathrm{T}} \mathbf{g}\right)_{\mathrm{bc}} \sin 2 \theta \sin \phi+\left(\mathbf{g}^{\mathrm{T}} \mathbf{g}\right)_{\mathrm{cc}} \cos ^{2} \theta
\end{aligned}
$$

where $\theta$ and $\phi$ are the polar and azimuthal angles of the magnetic field vector in the $a^{*}-b-c^{*}\left(a-b^{*}-c^{*}\right)$ coordinate system, respectively. The calculated $\mathbf{g}$-tensors are presented in Fig. 5 and in Fig. S12-S13 in ESI. $\dagger$ Some EPR lines for the compound $\mathbf{L}^{2}-\mathbf{B r}$ were too weak and/or too broad to be detected; therefore the calculation of $\mathbf{g}$-tensor for this complex was not performed. The principal values of the $\mathbf{g}$-tensors, obtained by diagonalization of the $\mathbf{g}^{\mathrm{T}} \mathbf{g}$-matrix at room temperature, are shown in Table 3, with the estimated error \pm 0.0001 . Powder averaged values $g_{a v}$ are calculated as: $g_{\mathrm{av}}=\sqrt{(1 / 3)\left(g_{x}^{2}+g_{y}^{2}+g_{z}^{2}\right)}$. The principal axis $g_{z}$ is directed along the $\mathrm{Cu}-\mathrm{X}$ bond (X ion at apical position), while $g_{x}$ and $g_{y}$ lay in the basal plane of the square pyramid. The obtained $g_{z}>g_{x} g_{y}$ values point out that $\mathrm{d}_{x^{2}-y^{2}}$ is the highest energy half-occupied orbital, ${ }^{36}$ which is in agreement with the square-pyramidal coordination around $\mathrm{Cu}(\mathrm{II})$ ions, as could be seen from Table 2 .

The powder EPR spectra of the investigated compounds recorded at $T=297 \mathrm{~K}$ and $T=80 \mathrm{~K}$ are shown in Fig. 6 . The spectra can be simulated using only $\mathrm{g}$-tensor parameters obtained from the single crystal measurements given in Table 3 while hyperfine A-tensors were taken to be zero. The powder spectra for the complex $\mathbf{L}^{2}-\mathbf{B r}$ are simulated assuming 


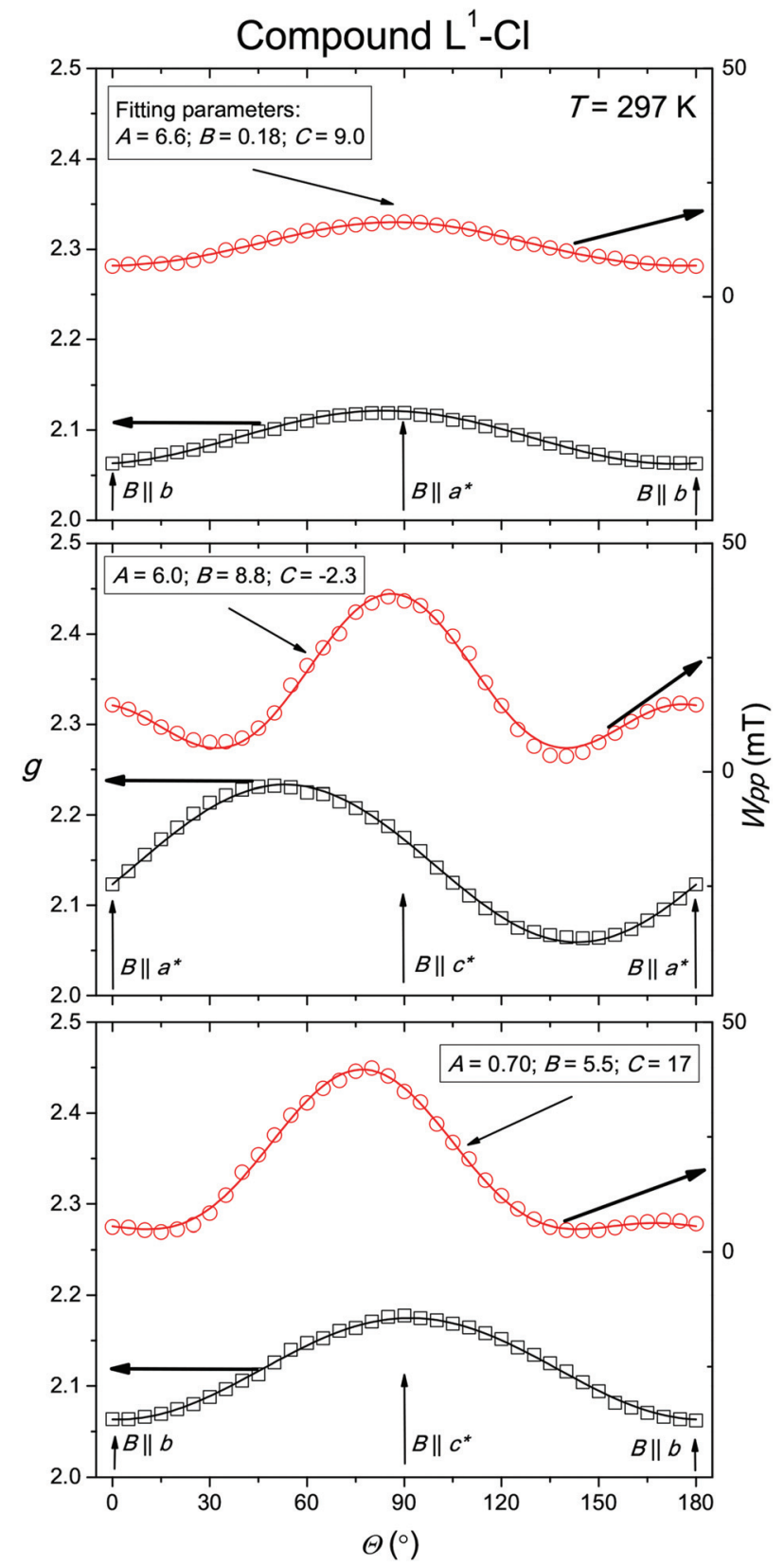

Fig. 5 Angular variation of the $g$-values (black squares) and the $W_{\mathrm{pp}}$ linewidths (red circles) of EPR lines for the single crystal of compound $\mathrm{L}^{1}-\mathrm{Cl}$, at room temperature, in three mutually perpendicular planes. Solid lines represent the fitted $g$-values with parameters given in Table 2 and the $W_{\mathrm{pp}}$ linewidths with parameters given in the figure, according to eqn (1) and (2), respectively.

Table 3 Principal and average values of the $\mathbf{g}$-tensors of the analyzed compounds at room temperature

\begin{tabular}{lllll}
\hline Compounds & $g_{x}$ & $g_{y}$ & $g_{z}$ & $g_{\text {av }}$ \\
\hline $\mathbf{L}^{\mathbf{1}}-\mathbf{C l}$ & 2.0559 & 2.0662 & 2.2335 & 2.1201 \\
$\mathbf{L}^{\mathbf{2}}-\mathbf{C l}$ & 2.0504 & 2.0628 & 2.2352 & 2.1178 \\
$\mathbf{L}^{\mathbf{1}}-\mathbf{B r}$ & 2.0459 & 2.0847 & 2.2525 & 2.1296 \\
$\mathbf{L}^{\mathbf{2}}-\mathbf{B r}$ & - & - & - & -
\end{tabular}

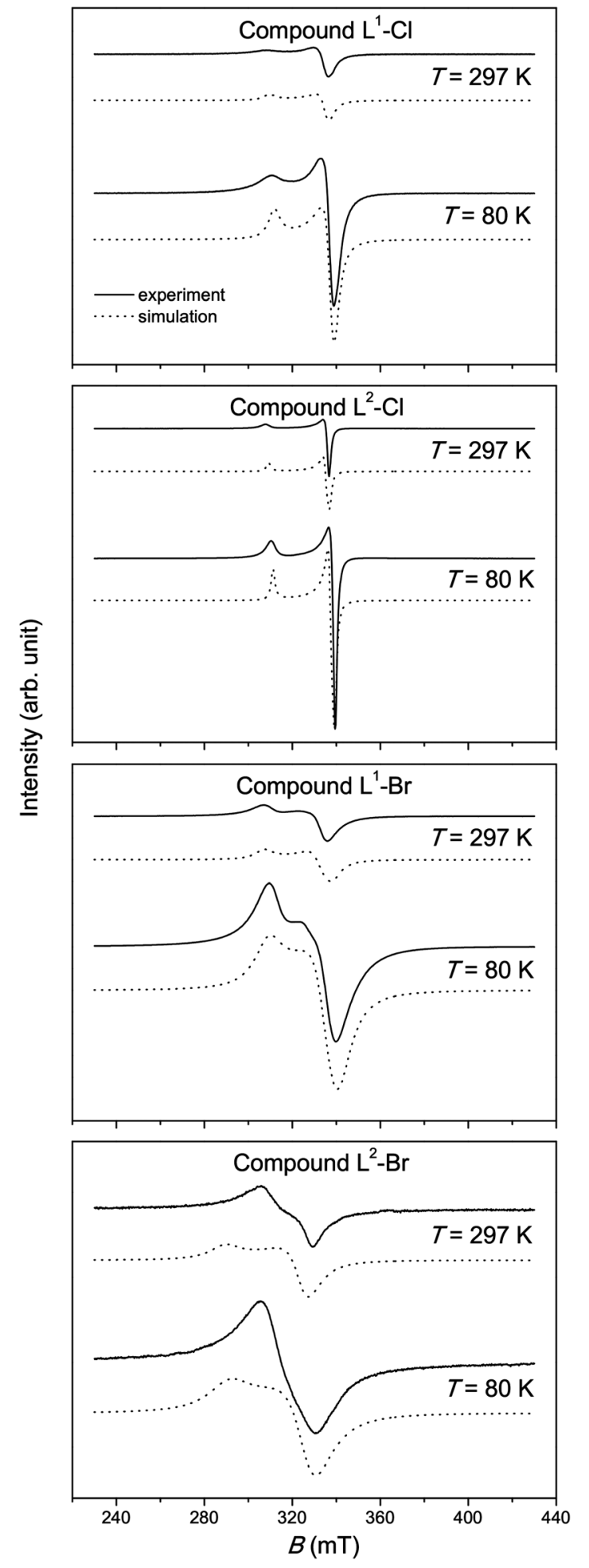

Fig. 6 Experimental (solid lines) and simulated (dotted lines) X-band EPR spectra of powdered samples of the compounds at the indicated temperatures.

the following parameters: $g_{x}=g_{y}=2.13$ and $g_{z}=2.39$. The spectra were simulated by EasySpin software ${ }^{37}$ using Lorentzian lineshapes, with different linewidths at different temperatures. 
The observed EPR linewidth data show a strong angular dependence, as could be seen in Fig. 5 and in Fig. S12-S14 in ESI. $\dagger$ Linewidth minima are observed for some angles $\theta$ between $0^{\circ}$ and $90^{\circ}$. A similar linewidth anisotropy has been observed for layered compounds. This behavior is in contrast to the $3 \mathrm{D}$ situation, where the linewidths show dependence $\left(1+\cos ^{2} \theta\right)$. The minimum lies close to the magic angle $\theta=55^{\circ}$ that is characteristic for low-dimensional systems and it corresponds to the secular part of the dipolar interaction $\left(3 \cos ^{2}\right.$ $\theta-1)^{2} \cdot{ }^{38}$ However, this term was not enough to explain the observed linewidth data and we have considered additional sources of EPR line broadening and narrowing. The data were fitted adequately, presented by solid lines in Fig. 5 and Fig. S12-S13 in ESI $\dagger$, by using the general expression: ${ }^{39}$

$$
\Delta W_{\mathrm{pp}}=A+B\left(3 \cos ^{2} \theta-1\right)^{2}+C \cos ^{2} \theta
$$

The $A$-term represents the isotropic contribution to the linewidth, the $B$-term describes the previously mentioned dipolar interaction, while the $C$-term could be related to anisotropic spin-spin interaction. The values of parameters $A, B$ and $C$ are given in Fig. 5 and in Fig. S12-S13 in ESI. $\dagger$ Hyperfine terms and contributions arising on the non-equivalence of the copper sites for compounds $\mathbf{L}^{\mathbf{1}}-\mathbf{C l}$ and $\mathbf{L}^{\mathbf{1}}-\mathbf{B r}$ were neglected in eqn (2).

The obtained results, the absence of hyperfine interactions (with the copper as well as two nitrogen nuclei), the unifying line effect for magnetically non-equivalent copper centers and Lorentzian-like EPR lines, reveal the presence of an exchange interaction in the compounds. However, the absence of the half-field EPR line shows that this interaction is not strong. By using linewidth analysis and the method of moments: ${ }^{40}$

$$
\Gamma_{\exp } \sim \gamma\left(\Gamma_{\mathrm{d}}\right)^{2} / \omega_{\text {exch }}
$$

where $\Gamma_{\exp }$ is the experimental linewidth, $\gamma$ is the gyromag-

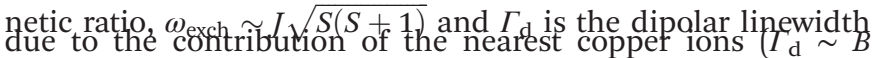
from eqn (2)), calculated as previously described, ${ }^{41}$ an exchange interaction parameter between copper(II) ions of the order of $|J| \sim 1 \mathrm{~cm}^{-1}$ could be obtained.

A plausible reason for the relatively weak exchange interaction observed is given by the fact that the unpaired electron in $\mathrm{d}_{x^{2}-y^{2}}$ orbital is localized in the basal plane of square pyramid and the orbital is pointing toward the four nearest neighbors of $\mathrm{Cu}(\mathrm{II})$ ions ( $\mathrm{N}, \mathrm{N}, \mathrm{O}$ and $\mathrm{X}$ ions), as could be seen in Fig. 3. Therefore, the two orbitals with unpaired electrons are situated in parallel planes, separated by $\sim 3.5 \AA$, a particularly unfavorable arrangement for strong exchange interactions to occur. ${ }^{42}$

\subsection{Magnetization study}

Temperature dependence of magnetization $M(T)$ of the investigated complexes is presented in Fig. 7. ${ }^{43}$ The observed magnetization, lower than expected for two independent copper(II) spins at low temperature, indicates antiferromagnetic interaction between spins in structural dimers for all four com-

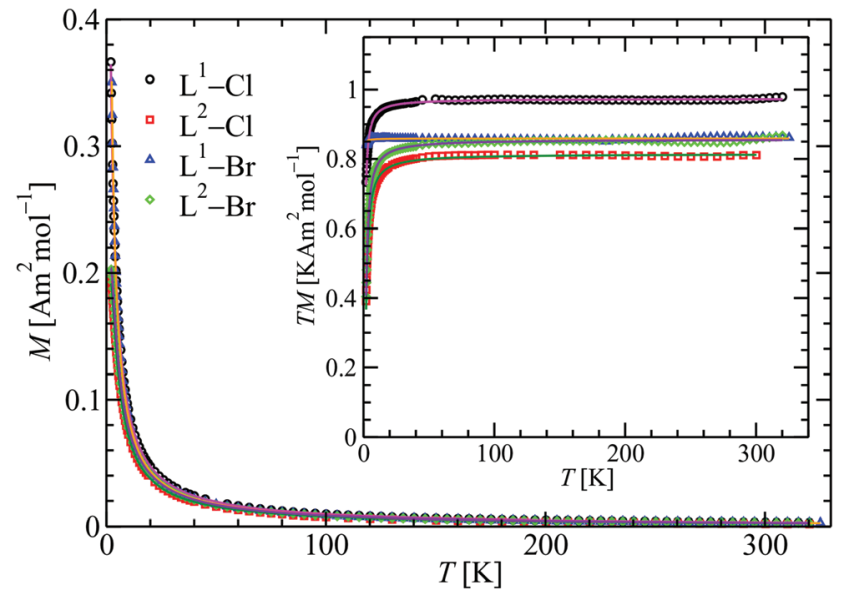

Fig. 7 Temperature dependence of magnetization, measured in a field of $0.1 \mathrm{~T}$. Inset: temperature dependence of the $T \cdot M$ product. Lines are fitting curves.

plexes. The interaction is weak, as could be clearly seen by looking at the inset of Fig. 7, where the product $M \cdot T(T)$ curve is shown. It deviates from the horizontal (paramagnetic) line below a few Kelvins only and therefore the molar magnetic susceptibility cannot be modelled using the Bleaney-Bowers expression for interacting spins in dimers. Instead, since $J$ is comparable to $g \beta H$, a more general approach, developed by Friedberg, should be used: ${ }^{44,45}$

$$
M=\frac{N g \beta \sinh (g \beta H / k T)}{\exp (|-2 J| / k T)+2 \cosh (g \beta H / k T)+1}
$$

$N, \beta$ and $k$ are the well known constants, $H$ is the applied field, the variable $T$ is temperature, $g$ is the effective $g$-factor and $J$ is the isotropic exchange interaction parameter within dimer, defined through the energy term $-2 J S_{1} \cdot S_{2}$. Besides the $g$ and $J$ fitting parameters, a small correction to the temperature independent core electron contribution is added. Fits of eqn (4) go very well through the measured magnetization points, as could be seen in Fig. 7. The fitting was performed in both $M(T)$ and $T \cdot M(T)$ forms giving approximately the same results. The obtained values are presented in Table 4 and standard deviation is included together with fitting error in parentheses.

The field dependence of magnetization $M(H)$ measured at temperature $2 \mathrm{~K}$ is presented in Fig. 8. An advantage of the Friedberg approach is the description of $M(H)$ curves up to

Table 4 Exchange interaction parameters $J$ and $g$-factors obtained from magnetization study

\begin{tabular}{llllll}
\hline & \multicolumn{2}{l}{ From $M(T)$} & & \multicolumn{2}{l}{ From $M(H)$} \\
\cline { 2 - 3 } Compound & $J\left(\mathrm{~cm}^{-1}\right)$ & $g$ & & $J\left(\mathrm{~cm}^{-1}\right)$ & $g$ \\
\hline $\mathbf{L}^{\mathbf{1}}-\mathbf{C l}$ & $-0.59(1)$ & $2.274(4)$ & & $-0.64(1)$ & $2.283(4)$ \\
$\mathbf{L}^{2}-\mathbf{C l}$ & $-1.19(3)$ & $2.06(2)$ & & $-1.10(4)$ & $2.00(2)$ \\
$\mathbf{L}^{\mathbf{1}}-\mathbf{B r}$ & $-0.07(3)$ & $2.149(9)$ & & $-0.13(3)$ & $2.17(9)$ \\
$\mathbf{L}^{2}-\mathbf{B r}$ & $-1.18(1)$ & $2.140(3)$ & & $-1.18(1)$ & $2.167(3)$
\end{tabular}




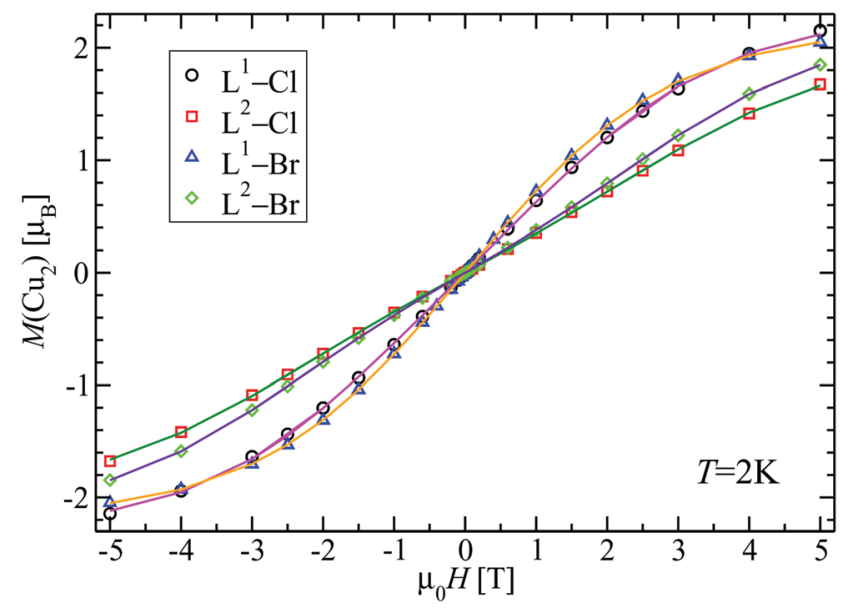

Fig. 8 Field dependence of magnetization. Lines are fitting curves.

arbitrary field $H$ at every temperature $T$. The results of fitting eqn (4) to the $M(H)$ data are presented also in Table 4.

The exchange parameters $J$ obtained from fitting $M(T)$ and $M(H)$ curves are mutually similar and they are also in agreement with values obtained from EPR spectra, thus confirming the consistency of two experimental methods. Small discrepancies between the obtained $g$-factors and the average EPR values given in Table 3 could derive from the uncertainty of absolute magnetization due to sample mass measurements. Additionally, the high degree of purity of the samples is confirmed through this analysis. Hence, from a magnetic point of view, the compounds can be considered as isolated halo-bridged copper(II) dimers. This result is in agreement with the previously crystallographically described infinite chain of dimeric units linked by $\mathrm{H}$-bonds via oxalamide groups. Due to the large size of the ligands, it can be seen that no magnetic interaction can take place through the organic bridge between dimers.

\subsection{Magneto-structural correlation}

The relationship between structural and magnetic properties in copper(II) dimer complexes has been intensively studied since 1970. It has been shown that exchange interaction is affected by several structural parameters such as the identity of the bridging atoms $(\mathrm{X})$, the $\mathrm{Cu}-\mathrm{Cu}^{\prime}$ distances, the bridging angles $\mathrm{Cu}-\mathrm{X}-\mathrm{Cu}^{\prime}(\alpha)$, the dihedral angles containing $\mathrm{Cu}$ ions and the coordination geometries around copper ions. ${ }^{5,9,46-50}$ For planar dihydroxo-bridged copper complexes, a simple, linear, correlation between the singlet-triplet separation $2 J$ and the angle $\alpha$ was reported. ${ }^{46-48}$ However, in the case of dihalo-bridged copper complexes, the wider variety of geometries available to such systems and the possibility for relatively low-lying halogens' d-orbitals to interact with copper orbitals make the overall picture more complicated. ${ }^{51}$ Generally, a strong correlation (parabolic curve with a maximum of ca. $33^{\circ} \AA^{-1}$ ) has been found between $2 J$ and the quotient $\alpha / R$, where $R$ is the longer (axial) $\mathrm{Cu}-\mathrm{Cl}$ distance. ${ }^{52}$ It is pointed out that for the values $31<\alpha / R<34.5$, the exchange interaction is ferromagnetic and for the values $\alpha / R<31$ or $\alpha / R>34.5$ the exchange interaction is antiferromagnetic. ${ }^{52}$ This is in agreement with the fact that $|J|$, always composed of ferro- and antiferromagnetic components, should have a minimal value. ${ }^{45,48}$ Ferromagnetic contributions are usually small but antiferromagnetic contributions are proportional to the square of the overlap integral between orbitals. Therefore, the resulting sign depends on the amplitude of that overlap. ${ }^{53}$ The above correlation rule is valid only for complexes with square-pyramidal arrangement of type II (pyramids share one base-to-apex edge with parallel basal planes). ${ }^{29}$

For complexes of type III (pyramids sharing a basal edge with coplanar basal planes), a linear dependence in the $2 J v s$. $\alpha / R$ graph is found. In other words, magneto-structural correlations of dichloro-bridged copper(II) complexes must take into account the relative orientation of square pyramids to each other, viz. coplanar, parallel and perpendicular. This is also in accordance with molecular orbital calculations that indicate different types of orbitals involved in each case. ${ }^{5}$ In this work, the experimental values $2 J=-1.2 \mathrm{~cm}^{-1}$ (with $\alpha / R=32.9^{\circ} \AA^{-1}$ ) and $2 J=-2.4 \mathrm{~cm}^{-1}$ (with $\alpha / R=34.3^{\circ} \AA^{-1}$ ) determined for dichloro-bridged complexes $\mathbf{L}^{\mathbf{1}}-\mathbf{C l}$ and $\mathbf{L}^{\mathbf{2}}-\mathbf{C l}$ respectively are in contrast with the correlation rule for type II compounds previously described $^{52}$ and add to other similar cases of inconsistency. ${ }^{11,54}$ However, the obtained results are quantitatively in agreement with other type II values, where the exchange interaction within dimer is generally $-10 \mathrm{~cm}^{-1}<J<10 \mathrm{~cm}^{-1}$.

For dibromo-bridged copper dimers, the situation is even more complicated. There is less information available for complexes bridged by $\mathrm{Br}$ compared to $\mathrm{Cl}$ and magneto-structural correlations are less studied for Br-bridged copper dimers. ${ }^{10} \mathrm{It}$ has been found that the previously mentioned correlation $2 J$ vs. $\alpha / R$ ratio is not valid for dibromo-bridged copper complexes. ${ }^{8,12}$ However, Landee and Greeney observed that the magnetic interaction strength can be correlated to the degree of non-planarity within the $\mathrm{Cu}$ basal plane ( $J$ vs. trans $\mathrm{Br}-\mathrm{Cu}-\mathrm{L}$ bridging angle). ${ }^{8}$ A similar correlation was presented by Rojo and coworkers who associated $J$ with the extent of distortion within the $\mathrm{Cu}$ basal plane and with the $\mathrm{Cu}-\mathrm{Br}$ (apical) distance, including also different types of geometry such as regular square pyramids, trigonal distorted square pyramids and tetrahedral distorted square pyramids. ${ }^{50}$ Additionally, Romero and coworkers found a difference between two groups of dibromo-bridged copper complexes following the Rodríguez classification. $^{29,55}$

Here, a simple correlation between singlet-triplet splitting $2 J$ and Reedijk's parameter $\tau$ of trigonal distortion is presented. The selected structural and magnetic data for complexes reported in the literature ${ }^{56-62}$ are shown in Table 8 in ESI, $\dagger$ while the related graph of $2 J v s$. parameter $\tau$ is shown in Fig. 9.

It should be noted that trigonal bipyramid could be considered as the limit case of distortion of square pyramid via the Berry mechanism. ${ }^{55}$ It could be seen that only one complex is ferromagnetically coupled while most complexes are weakly antiferromagnetically coupled with $|J|<10 \mathrm{~cm}^{-1}$, including 


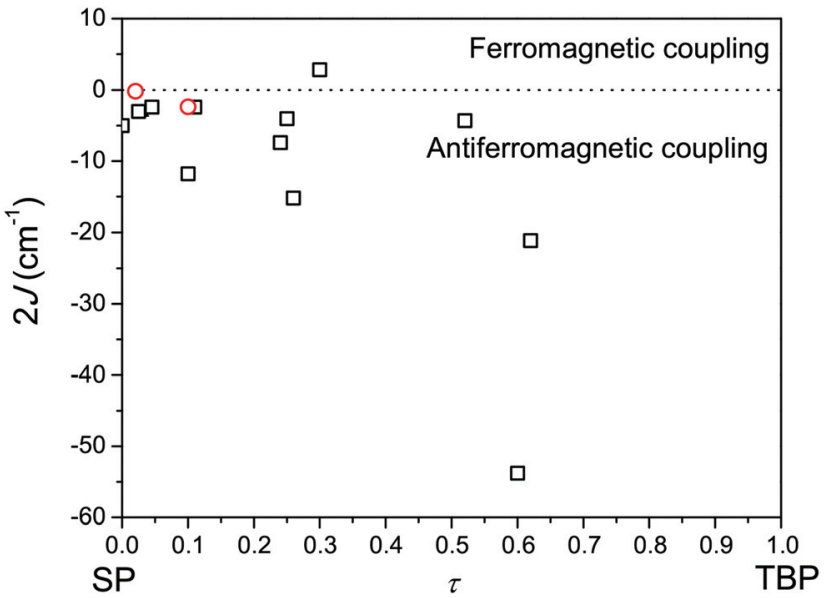

Fig. 9 Magneto-structural correlations for dibromo-bridged copper(I) complexes: plot of the singlet-triplet splitting $2 \mathrm{~J}\left(\mathrm{~cm}^{-1}\right)$ vs. Reedijk's trigonal distortion parameter $\tau$. Black squares present literature data given in Table 8 in $\mathrm{ESI}, \dagger$ while red circles present values obtained for $\mathrm{L}^{1}-\mathrm{Br}$ and $\mathrm{L}^{2}-\mathrm{Br}$ complexes in this work. $\mathrm{SP}=$ square pyramid; $\mathrm{TBP}=$ trigonal bipyramid.

the bromide complexes of this work. This is in agreement with Kahn's observation that 95\% of copper(II) dinuclear compounds have antiferromagnetic interaction. ${ }^{2}$ The strongest couplings are shown by trigonal bipyramid complexes. The observed behavior is relatively easy to be explained. For example, for type II complexes, the exchange pathway takes place through an interaction between copper $d_{x^{2}-y^{2}}$ situated in the basal plane and the apical p bromo-orbital. Therefore, for small $\tau$ values, the density of magnetic orbital out of the plane is small and superexchange coupling would be weak or slightly ferromagnetic, while for an ideal square-pyramid geometry $(\tau=0)$, zero coupling is expected. For distorted geometry around copper ions, magnetic orbitals are more mixed with bromo orbitals and exchange interaction would be stronger. For trigonal-bipyramid geometry $(\tau=1)$, magnetic orbitals are on $\mathrm{d}_{\mathrm{z}}{ }^{2}$ and the overlap would again be zero. ${ }^{10}$ The lack of dibromo-bridged copper complexes featuring geometries within the $\tau=0.65-1$ range prevents to verify such an anticipated tendency. Finally, the hypothesis that bromide dimers might have stronger antiferromagnetic couplings than the chloride analogues ${ }^{10,50,63}$ is not supported by our data as well as by those of others. ${ }^{8}$

\section{Conclusions}

In summary, we have designed and synthesized a set of four dihalo-bridged copper(II) dimers making use of oxalyl retropeptide ligands. Single-crystal X-ray diffraction analysis reveals that, in all cases, the $\mathrm{Cu}$ (II) ion is penta-coordinated by a tridentate NNO ligand and by two halo-ions $(\mathrm{Cl}$ or $\mathrm{Br})$ in an ideal or near ideal square-pyramidal environment with $\tau=0.00-$ 0.17. Single crystal EPR and SQUID magnetization studies on the dinuclear complexes confirm the presence of weak anti- ferromagnetic interactions between the copper ions. By considering the data available in the literature for similar dihalobridged copper(II) complexes, it is evident that more studies and data analyses are required in order to obtain better and more widely applicable magneto-structural correlations, especially for the less common Br-derivatives. Finally, the onedimensional hydrogen bonded polynuclear arrangements observed in the solid state suggest the potential application of such ligands as building blocks for the self-assembly of molecule-based magnetic materials. Work along these lines is in progress and will be reported in due course.

\section{Acknowledgements}

This research was supported by the Ministry of Science, Education and Sports of the Republic of Croatia (projects 0980982915-2939, 098-0982904-2912, 119-1193079-1084 and 1191191458-1017) and the Programma per Giovani Ricercatori "Rita Levi Montalcini" 2009.

\section{References}

1 (a) I. A. Koval, P. Gamez, C. Belle, K. Selmeczi and J. Reedijk, Chem. Soc. Rev., 2006, 35, 814-840; (b) S. Tardito, I. Bassanetti, C. Bignardi, L. Elviri, M. Tegoni, C. Mucchino, O. Bussolati, R. Franchi-Gazzola and L. Marchiò, J. Am. Chem. Soc., 2011, 133, 6235-6242; (c) P. Hirva, A. Nielsen, A. D. Bond and C. J. McKenzie, J. Phys. Chem. B, 2010, 114, 11942-11948.

2 O. Kahn, Molecular Magnetism, Wiley-VCH Inc., 1993.

3 (a) O. Kahn, Y. Pei and Y. Journaux, Inorganic Materials, John Wiley and Sons, Chichester, U.K., 1992; (b) O. Kahn, Acc. Chem. Res., 2000, 33, 647-657; (c) E. Pardo, J. Faus, M. Julve, F. Lloret, M. C. Muñoz, J. Cano, X. Ottenwaelder, Y. Journaux, R. Carrasco, G. Blay, I. Fernández and R. Ruiz-García, J. Am. Chem. Soc., 2003, 125, 10770-10771.

4 A. Rodríguez-Fortea, P. Alemany, S. Alvarez and E. Ruiz, Inorg. Chem., 2002, 41, 3769-3778.

5 M. Rodríguez, A. Llobet and M. Corbella, Polyhedron, 2000, 19, 2483-2491.

6 B. Murphy and B. Hathaway, Coord. Chem. Rev., 2003, 243, 237-262.

7 (a) A. Sasmal, S. Shit, C. Rizzoli, H. Wang, C. Desplanches and S. Mitra, Inorg. Chem., 2012, 51, 10148-10157; (b) K. Skorda, T. C. Stamatatos, A. P. Vafiadis, A. T. Lithoxoidou, A. Terzis, S. P. Perlepes, J. Mrozinski, C. P. Raptopoulou, J. C. Plakatouras and E. G. Bakalbassis, Inorg. Chim. Acta, 2005, 358, 565-582; (c) T.-L. Hu, J.-R. Li, C.-S. Liu, X.-S. Shi, J.-N. Zhou, X.-H. Bu and J. Ribas, Inorg. Chem., 2006, 45, 162-173; (d) M. Du, Y.-M. Guo, X.-H. Bu, J. Ribas and M. Monfort, New J. Chem., 2002, 26, 939-945.

8 C. P. Landee and R. E. Greeney, Inorg. Chem., 1986, 25, 3771-3775. 
9 T. Rojo, M. I. Arriortua, J. Ruiz, J. Darriet, G. Villeneuve and D. Beltran-Porter, J. Chem. Soc., Dalton Trans., 1987, 285-291.

10 S. Sain, T. K. Maji, D. Das, J. Cheng, T.-H. Lu, J. Ribas, M. S. El Fallah and N. R. Chaudhuri, J. Chem. Soc., Dalton Trans., 2002, 1302-1306.

11 M. Du, Y.-M. Guo, X.-H. Bu, J. Ribas and M. Monfort, New J. Chem., 2002, 26, 645-650.

12 D. K. Towle, S. K. Hoffmann, W. E. Hatfield, P. Singh, P. Chaudhuri and K. Wieghardt, Inorg. Chem., 1985, 24, 4393-4397.

13 (a) M.-C. Dul, E. Pardo, R. Lescouëzec, Y. Journaux, J. Ferrando-Soria, R. Ruiz-García, J. Cano, M. Julve, F. Lloret, D. Cangussu, C. L. Pereira, H. O. Stumpf, J. Pasán and C. Ruiz-Pérez, Coord. Chem. Rev., 2010, 254, 22812296; (b) R. Ruiz, J. Faus, F. Lloret, M. Julve and Y. Journaux, Coord. Chem. Rev., 1999, 193-195, 1069-1117.

14 Z. Džolić, M. Cametti, D. Milić and M. Žinić, Chem. - Eur. J., 2013, 19, 5411-5416.

15 Agilent, CrysAlis PRO, Agilent Technologies UK Ltd, Yarnton, U. K., 2011.

16 G. M. Sheldrick, Acta Crystallogr., Sect. A: Fundam. Crystallogr., 2008, 64, 112-122.

17 P. Emsley, B. Lohkamp, W. G. Scott and K. Cowtan, Acta Crystallogr., Sect. D: Biol. Crystallogr., 2010, 66, 486-501.

18 L. J. Farrugia, J. Appl. Crystallogr., 1999, 32, 837-838.

19 A. L. Spek, Acta Crystallogr., Sect. D: Biol. Crystallogr., 2009, 65, 148-155.

20 C. F. Macrae, I. J. Bruno, J. A. Chisholm, P. R. Edgington, P. McCabe, E. Pidcock, L. Rodriguez-Monge, R. Taylor, J. Van De Streek and P. A. Wood, J. Appl. Crystallogr., 2008, 41, 466-470.

21 L. J. Farrugia, J. Appl. Crystallogr., 1997, 30, 565.

22 Persistence of Vision Pty. Ltd, Persistence of Vision Raytracer (POV-Ray; Version 3.6).http://www.povray.org/, 2004.

23 (a) L. Frkanec and M. Žinić, Chem. Commun., 2010, 46, 522-537; (b) Z. Džolić, M. Cametti, A. Dalla Cort, L. Mandolini and M. Žinić, Chem. Commun., 2007, 35353537; (c) A. Guerrero-Martínez, B. Auguié, J. L. AlonsoGómez, Z. Džolić, S. Gómez-Graña, M. Žinić, M. M. Cid and L. M. Liz-Marzán, Angew. Chem., Int. Ed., 2011, 50, 54995503; (d) G. De Paoli, Z. Džolić, F. Rizzo, L. De Cola, F. Vögtle, W. Müller, G. Richardt and M. Žinić, Adv. Funct. Mater., 2007, 17, 821-828; (e) Z. Džolić, K. Wolsperger and M. Žinić, New J. Chem., 2006, 30, 1411-1419.

24 A. Cornia, A. C. Fabretti, F. Ferraro, D. Gatteschi and A. Giusti, J. Chem. Soc., Dalton Trans., 1993, 3363-3366.

25 J.-K. Tang, Y. Ou-Yang, H.-B. Zhou, Y.-Z. Li, D.-Z. Liao, Z.-H. Jiang, S.-P. Yan and P. Cheng, Cryst. Growth Des., 2005, 5, 813-819.

26 L. Shi, B. Cai, G. Huang, J.-Z. Wu and Y. Yu, Z. Anorg. Allg. Chem., 2011, 637, 306-311.

27 (a) F. Lloret, M. Julve, J. Faus, Y. Journaux, M. PhilocheLevisalles and Y. Jeannin, Inorg. Chem., 1989, 28, 37023706; (b) H.-X. Zhang, B.-S. Kang, Z.-Y. Zhou, A. S. C. Chan, Z.-N. Chen and C. Ren, J. Chem. Soc., Dalton Trans., 2001,
1664-1669; (c) L.-H. Xu, H.-X. Wang and L.-N. Zhu, J. Coord. Chem., 2012, 65, 1051-1061.

28 A. W. Addison, T. N. Rao, J. Reedijk, J. van Rijn and G. C. Verschoor, J. Chem. Soc., Dalton Trans., 1984, 13491356.

29 M. Rodríguez, A. Llobet, M. Corbella, A. E. Martell and J. Reibenspies, Inorg. Chem., 1999, 38, 2328-2334.

30 (a) D. W. Phelps, W. H. Goodman and D. J. Hodgson, Inorg. Chem., 1976, 15, 2266-2270; (b) M. Melník, M. Kabešovå, M. Koman, L. Macåškovå, J. Garaj, C. E. Holloway and A. Valent, J. Coord. Chem., 1998, 45, 147-359; (c) B. Antonioli, B. Buchner, J. K. Clegg, K. Gloe, K. Gloe, L. Gotzke, A. Heine, A. Jager, K. A. Jolliffe, O. Kataeva, V. Kataev, R. Klingeler, T. Krause, L. F. Lindoy, A. Popa, W. Seichter and M. Wenzel, Dalton Trans., 2009, 4795-4805; (d) C. P. Pradeep and S. K. Das, Polyhedron, 2009, 28, 630-636.

31 S. J. Brown, X. Tao, T. A. Wark, D. W. Stephan and P. K. Mascharak, Inorg. Chem., 1988, 27, 1581-1587.

32 (a) A. Castiñeiras, A. G. Sicilia-Zafra, J. M. González-Pérez, D. Choquesillo-Lazarte and J. Niclós-Gutiérrez, Inorg. Chem., 2002, 41, 6956-6958; (b) Z. D. Tomić, V. M. Leovac, S. V. Pokorni, D. Zobel and S. D. Zarić, Eur. J. Inorg. Chem., 2003, 2003, 1222-1226; (c) Z. D. Tomić, S. B. Novaković and S. D. Zarić, Eur. J. Inorg. Chem., 2004, 2004, 2215-2218; (d) Z. D. Tomić, D. Sredojević and S. D. Zarić, Cryst. Growth Des., 2006, 6, 29-31.

33 (a) G. A. Bogdanović, A. Spasojević-de Biré and S. D. Zarić, Eur. J. Inorg. Chem., 2002, 2002, 1599-1602; (b) Y.-f. Jiang, C.-j. Xi, Y.-z. Liu, J. Niclós-Gutiérrez and D. ChoquesilloLazarte, Eur. J. Inorg. Chem., 2005, 2005, 1585-1588; (c) D. Sredojević, G. A. Bogdanović, Z. D. Tomić and S. D. Zarić, CrystEngComm, 2007, 9, 793-798; (d) V. B. Medaković, G. A. Bogdanović, M. K. Milčić, G. V. Janjić and S. D. Zarić, J. Inorg. Biochem., 2012, 117, 157-163.

34 H. Yokoi and S. Ohsawa, Bull. Chem. Soc. Jpn., 1973, 46, 2766-2768.

35 J. A. Weil, J. R. Bolton and J. E. Wertz, Electron Paramagnetic Resonance, John Wiley and Sons, Inc., New York, 1994.

36 E. Garribba and G. Micera, J. Chem. Educ., 2006, 83, 1229.

37 S. Stoll and A. Schweiger, J. Magn. Reson., 2006, 178, 42-55.

38 L. J. De Jongh, Magnetic Properties of Layered Transition Metal Compounds, Kluwer Academic Publishers, The Netherlands, 1990.

39 (a) R. Calvo, Appl. Magn. Reson., 2007, 31, 271-299; (b) P. Levstein, C. Steren, A. Gennaro and R. Calvo, Chem. Phys., 1988, 120, 449-459; (c) A. Gennaro, P. Levstein, C. Steren and R. Calvo, Chem. Phys., 1987, 111, 431-438; (d) R. D. Willett, F. H. Jardine, I. Rouse, R. J. Wong, C. P. Landee and M. Numata, Phys. Rev. B: Condens. Matter, 1981, 24, 5372-5381.

40 (a) J. E. Wertz and J. R. Bolton, Electron Spin Resonances, Elementary Theory and Practical Applications, McGraw-Hill, New York, 1972; (b) C. P. Poole Jr., Electron Spin Resonance: A Comprehensive Treatise on Experimental Techniques, John Wiley and Sons, Inc., New York, 1983. 
41 L. Androš, M. Jurić, P. Planinić, D. Žilić, B. Rakvin and K. Molčanov, Polyhedron, 2010, 29, 1291-1298.

42 I. Bkouche-Waksman, S. Sikorav and O. Kahn, J. Crystallogr. Spectrosc. Res., 1983, 13, 303-310.

43 Results obtained by fitting the data above $20 \mathrm{~K}$ using the standard Curie-Weiss model can be found in ESI, Fig. S15. $\dagger$

44 B. E. Myers, L. Berger and S. A. Friedberg, J. Appl. Phys., 1969, 40, 1149-1151.

45 C. R. Lucas, S. Liu and L. K. Thompson, Inorg. Chem., 1990, 29, 85-88.

46 V. H. Crawford, H. W. Richardson, J. R. Wasson, D. J. Hodgson and W. E. Hatfield, Inorg. Chem., 1976, 15, 2107-2110.

47 D. Y. Jeter, D. L. Lewis, J. C. Hempel, D. J. Hodgson and W. E. Hatfield, Inorg. Chem., 1972, 11, 1958-1960.

48 P. J. Hay, J. C. Thibeault and R. Hoffmann, J. Am. Chem. Soc., 1975, 97, 4884-4899.

49 K. Das, A. Datta, C. Sinha, J.-H. Huang, E. Garribba, C.-S. Hsiao and C.-L. Hsu, Chem. Open, 2012, 1, 80-89.

50 T. Rojo, M. I. Arriortua, J. L. Mesa, R. Cortes, G. Villeneuve and D. Beltran, Inorg. Chim. Acta, 1987, 134, 59-66.

51 W. E. Marsh, T. L. Bowman, C. S. Harris, W. E. Hatfield and D. J. Hodgson, Inorg. Chem., 1981, 20, 3864-3867.
52 W. E. Marsh, K. C. Patel, W. E. Hatfield and D. J. Hodgson, Inorg. Chem., 1983, 22, 511-515.

53 E. Colacio, M. Ghazi, R. Kivekäs and J. M. Moreno, Inorg. Chem., 2000, 39, 2882-2890.

54 X.-H. Jin, L.-X. Cai, J.-K. Sun, Z.-F. Ju and J. Zhang, Inorg. Chem. Commun., 2010, 13, 86-89.

55 M. Romero, J. Salas, M. Quirós, M. P. Sánchez, J. Romero and D. Martín, Inorg. Chem., 1994, 33, 5477-5481.

56 P. Singh, D. Y. Jeter, W. E. Hatfield and D. J. Hodgson, Inorg. Chem., 1972, 11, 1657-1661.

57 M. Megnamisi-Belombe and M. A. Novotny, Inorg. Chem., 1980, 19, 2470-2473.

58 W. E. Marsh, T. L. Bowman, W. E. Hatfield and D. J. Hodgson, Inorg. Chim. Acta, 1982, 59, 19-24.

59 R. Li, B. Moubaraki, K. S. Murray and S. Brooker, Dalton Trans., 2008, 6014-6022.

60 E. Luukkone and A. Pajunen, Suom. Kemistil. B, 1973, 46, 292-296.

61 R. B. Wilson, W. E. Hatfield and D. J. Hodgson, Inorg. Chem., 1976, 15, 1712-1716.

62 J. T. Blanchette and R. D. Willett, Inorg. Chem., 1988, 27, 843-849.

63 W. E. Estes, J. R. Wasson, J. W. Hall and W. E. Hatfield, Inorg. Chem., 1978, 17, 3657-3664. 